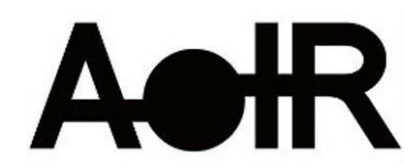

Selected Papers of \#AoIR2020:

The 22nd Annual Conference of the

Association of Internet Researchers

Virtual Event / 13-16 Oct 2021

\title{
FROM TOP-DOWN TO BOTTOM-UP: POLITICAL IMAGE MANAGEMENT AND THE PRESERVATION OF WHITE SUPREMACY THROUGH VISUALS AND MEMES ON SOCIAL MEDIA PLATFORMS
}

\author{
Rachel Winter \\ University of Central Florida \\ Julia DeCook \\ Loyola University Chicago
}

Social media platforms play an increasing role in politics, facilitating the circulation of populist texts disseminated by politicians, official campaign media, and user-generated content, all of which contribute to voters' perceptions of politicians and political issues. The networks and affordances of social media platforms allow for the development of an individualized, affective connection with voters, which is a particularly important strategy for far-right politicians, who are often stigmatized. Furthermore, social media enables the circulation of user-generated materials in a form of digital political participation, allowing citizens to respond in real-time to political developments. While digital political participation ostensibly offers the potential for the expression of marginalized perspectives, digital texts predominantly emphasize and enforce existing hierarchies, particularly the supremacy of whiteness. This panel explores visuals and memes circulated on social media through the lenses of platform studies, whiteness studies, nostalgia, and Critical Discourse Analysis. By examining both "top-down" media disseminated by public figures and "bottom-up" user-generated content, this panel provides an in-depth understanding of the social media ecosystems that work to preserve and extend far-right values and white supremacy.

Rachel Winter focuses on the influence of official campaign materials on user-generated content, as well as the impacts of both on candidate image management and the racial hierarchy of the United States. An analysis of representations of race in user-generated Rafael "Ted" Cruz and Robert "Beto" O'Rourke memes reveals an embedded valuation of whiteness and white supremacy to the detriment of other racial demographics. Political memes collected from Facebook, Twitter, Instagram, Tumblr, and Reddit uphold the importance of the white racial identity of candidates and, in so doing, attempt to preserve White American identities from the perceived threat of multiculturalism embodied in racially diverse politicians and their constituents.

Suggested Citation (APA): Winter, R., and DeCook, J. (2021, October). From top-down to bottom-up: Political image management and the preservation of white supremacy through visuals and memes on social media platforms. Panel presented at AoIR 2021: The 22nd Annual Conference of the Association of Internet Researchers. Virtual Event: AolR. Retrieved from http://spir.aoir.org. 
Julia DeCook examines nostalgia and chronotopes in alt-right memes, contending that the emphasis on "tradition" over "progress" is an attempt to unify the alt-right and preserve white identity and supremacy from threats of globalization and feminism. The alt-right creates virtual nation-states that use consistent linguistic strategies to enable these groups to engage in a form of collective action. Examining white supremacist memes from Reddit and Instagram, Panelist 2 explores the ways that time, memory, and the abstract conception of "the past" are used in digital propaganda to appeal to younger voters and emphasize the myth that whiteness must be protected from the threat of multiculturalism. 


\title{
“BETO” AND "TED”: AUTHENTIC PERFORMANCE OF ETHNIC IDENTITY AND THE PRIMACY OF THE WHITE PERSPECTIVE
}

\author{
Rachel Winter \\ University of Central Florida
}

The development and increasing popularity of mass communication technologies has contributed to the growing importance of celebrity status to political success, as well as the necessity of mediated candidate image management (Wheeler, 2007, p. 33). Branding, a marketing technique, can be used to develop conceptual links between aspects of "economic management...[and] policy commitments" and "emotional attractions...such as 'one of us,' authenticity, approachability, and attractiveness" (Scammell, 2014, p. 82). In a post-broadcast democracy, media consumption is fragmented; some citizens choose to avoid news content while others increasingly participate in non-traditional political activity (Wilson, 2011, pp. 446-7). This participation can take the form of "candidate image building" (Penney, 2017, p. 100), which builds on source materials, in this case "the texts produced by journalists and politicians in the elite public sphere" (Wilson, 2011, p. 449). These texts are adapted by users to further develop their favored politician's brand and, in turn, their following and chances for electoral success (Penney, 2017, p. 103).

While citizens have a wide range of options for producing digital media, memes in particular are easily created, modified, and circulated (Kligler-Vilenchik \& Thorson, 2016, p. 1997), making them a popular choice for contributing to candidate branding. Although overtly the purpose of memes about political candidates is to provide surfacelevel criticisms or support for the candidates, examining the implicit values in the memes can also provide information about the beliefs of the creators/circulators of the memes, as well as their perception of their audience. Examining depictions of race in political memes can thus provide insight regarding voter perceptions of race, power, and representation, as well as the manner in which memes can be used to challenge - or uphold - valuation of whiteness and white supremacy.

This study was guided by the following research questions, using the 2018 Texas midterm election as a case study:

1. How did political fans incorporate representations of race in Beto O'Rourke and Ted Cruz memes in the months leading up to, and directly following, the November 2018 election?

2. What do racially focused memes reveal about Conservative and Liberal voters' candidate preferences and perceptions of racial hierarchies in the United States?

\section{Data Collection and Analysis}

To answer the above research questions, I collected memes from pro-Cruz and proO'Rourke communities on Facebook, Twitter, Instagram, Reddit, and Tumblr from the period of September 1, 2018 through November 14, 2018. I used Critical Discourse Analysis (CDA) to assess the content of memes to determine trends in the manners in 
which voters represented race in O'Rourke and Cruz memes. Discourse "does not just contribute to the shaping and reshaping of social structures but also reflects them" (Jorgensen \& Phillips, 2002, p. 61). In this same manner, user-generated political memes not only shape the way users participate in politics but also reflect the current structure of politics.

\section{Memes and the Preservation of White Supremacy}

Despite conceptions of the United States as a "nation of immigrants," white residents of European descent have traditionally held positions of privilege and power. As the number of non-white immigrants increases, white residents resort to "racialization, racial stereotyping, and prejudice" to protect the existing racial hierarchy (Leitner, 2012, p. 829). "Othering" non-white racial identities defines them as existing outside of mainstream American culture and identity, implying that non-white immigrants (and, indeed, native residents) must conform to white "values and norms" to be accepted (Leitner, 2012, p. 828).

In general, memes tend to enforce existing racial hierarchies; Matias (2020) found that digital texts like memes largely support hegemonic valuation of whiteness, reinforcing white supremacist views already entrenched in American society. A white supremacist apparatus is so embedded in United States' racial ideology that the enforcement of this ideology in memes and other digital content is often overlooked. Although white supremacy is often "latent and subliminal" (Matias, 2020, p. 15) in user-generated content, it works to uphold and enforce existing racial hierarchies that privilege whiteness and white individuals. Despite an increasing number of people of color online (Krogstad, 2015), the Internet largely remains a space largely dominated by whitecentric discourse.

This paper explores similar trends in political memes during the Texas 2018 election. Despite the growing role of Hispanic Texans in the Texas electorate, the collected memes predominantly privilege whiteness and the white perspective and were created and shared for an English-speaking audience. As Dyer (1997, p. 47) explained, the indeterminate nature of white as color/non-color is ideal for designating a population that is both "particular and nothing in particular." Being white involves fulfilling strict (but unclear) criteria; however, whiteness is also considered the "default" human quality. Any identities existing outside the white race are defined by their differences from this "default."

In addition, this paper argues that memes attempting to persuade racial minority voters emphasize characteristics of non-white racial identity, belying a belief that racial minorities determine their voting preferences based on shared racial identity rather than candidates' platforms and proposed policies. According to white supremacist beliefs, race is the most important defining characteristic, and therefore determines decisions related to voting. It is ultimately clear that the political meme creators in this study also perceive racial identity as an important marker of authenticity, revealing that the (presumably) white creators and posters of these memes strongly associate "authentic" identities with the performance of racial and place-based characteristics. 
Discourse facilitated by political memes shares similarities with other popular media representations of race, reproducing the default status of whiteness and representing audiences of color as niche interests. Thus, despite the potential for user-generated content to challenge existing power structures in the United States and represent alternative perspectives, political memes largely reproduce and enforce existing racial hierarchies while Othering minority populations. Like other digital texts, political memes act as an apparatus for preserving white identity and supremacy in the United States against the perceived threat of multiculturalism.

\section{References}

Dyer, R. (1997). White. New York, NY: Routledge.

Jorgensen, M., \& Phillips, L. J. (2002). Discourse analysis as theory and method. London: Sage. http://www.mrdowoportal.com/uploads/1/0/1/8/10183165/_discourse_analysis_a s_theory_and_method.pdf

Kligler-Vilenchik, N., \& Thorson, K. (2016). Good citizenship as a frame contest: Kony2012, memes, and critiques of the networked citizen. New Media \& Society, 18(9), 1993-2011. https://doi.org/10.1177/1461444815575311

Krogstad, J. M. (2015). Social media preferences vary by race and ethnicity. Pew Research. https://www.pewresearch.org/fact-tank/2015/02/03/social-mediapreferences-vary-by-race-and-ethnicity/

Leitner, H. (2012). Spaces of encounters: Immigration, race, class, and the politics of belonging in small-town America. Annals of the Association of American Geographers, 102(4), 828-846. DOI: 10.1080/00045608.2011.601204

Matias, C. E. (2020). Do you SEE the words coming out of that text?: Seeing whiteness in digital text. International Journal of Multicultural Education, 22(2), 14-29.

Penney, J. (2017). The citizen marketer. Oxford Scholarship Online. DOI:10.1093/acprof:oso/9780190658052.003.0004

Rogers, R., Malancharuvil-Berkes, E., Mosley, M., Hui, D., \& G. O. Joseph. (2005). Critical discourse analysis in education: A review of the literature. Review of Educational Research, 75(3), 365-416.

Scammell, M. (2014). Consumer democracy: The marketing of politics. Cambridge, MA: Cambridge University Press.

Wheeler, M. (2013). Celebrity politics. Malden, MA: Polity Press.

Wilson, J. (2011). Playing with politics: Political fans and Twitter faking in postbroadcast democracy. Convergence: The Journal of Research into New Media Technologies, 17(4), 445-461. https://doiorg.ezproxy.net.ucf.edu/10.1177/1354856511414348 


\section{"REJECT PROGRESS, EMBRACE TRADITION": CHRONOTOPES AND THE NOSTALGIC PAST IN WHITE SUPREMACIST MEMES}

Julia R. DeCook, PhD

Loyola University Chicago

\section{Introduction}

"The West is not in the West. It is a project, not a place." - Édouard Glissant (1992, p. 2)

The project of the West has spread to the digital realm. The rise of nationalism in the United States and Europe is primarily built upon the foundations of a white identity that transcends material borders. These nationalist movements believe that pluralistic and multicultural societies are a threat to white identity itself. Social movements that fall under the umbrella term of the alt-right often make invocations to western civilization, which is ambiguously loaded with multiple meanings but at its core is primarily focused upon white supremacy. Memes are more often than not created by everyday users and members of online communities, making them a quotidian part of life online. Through the creation of a virtual nation state, these boundaries are constantly being expanded by netizens who all share the similar sentiment: Western civilization is under attack by globalization and feminism.

The alt right despite its fractures and disagreements are bound together by a shared language, and it can be argued that the alt right is less a political ideology and more a way of speaking (Hodge \& Hallgrimsdottir, 2019). A shared language is the glue that binds people together; or in the words of Anderson, language is what creates the nation, not blood (Anderson, 2006). The mentality that is created through constant consumption of these materials and the creation of them through memes and alternative online communities enable these groups to engage in a form of collective action. Many of the memes harken back to and appeal to a sense of loss, of humiliation, and of regaining what was "stolen" from the members of these groups. Particularly, many of these memes mock feminism, progressive politics, and racial justice initiatives; and in white supremacist movements, the highest duty and honor of a white man is to preserve the heteropatriarchal, white family (Daniels, 2009). Relying on these white supremacist beliefs that undergirds much of U.S. policy, culture, and myth that whiteness must be protected, the memes and other digital artifacts that circulate often rely on the invocation of the past.

The role of myth in the perpetuation of white supremacist rhetoric is critical in understanding not only the persistence of white supremacy, but also its continued appeal to younger audiences. The myth of white supremacy is sold in not just nostalgic renderings of the past, where white women raised white children and white men ruled the world, but also through memes and other digital artifacts that celebrate the past and urge younger generations to reject "progress" and to "embrace tradition." Examining white supremacist memes from reddit and Instagram, this paper aims to uncover the ways that time, memory, and the abstract conception of "the past" are used in these modes of digital propaganda. Indeed, white supremacist myths shape racial attitudes 
that impact laws, policy, and our broader culture, serving as the very foundation of U.S. ideals and norms (Hughes, 2018). Using Bakhtin's conception of chronotopes, the purpose of this study will be to uncover how time, memory, and the abstract conception of "the past" feed into and perpetuate the project of "the West" in white supremacist memes.

\section{Research Questions}

The research questions that guide this study are:

1. How do white supremacist memes use time and memory in their iconography and text?

2. To what extent do these memes rely on chronotopes (i.e. the relations and implications of space-time) in their rhetoric?

a. How are chronotopes used to reinforce the relationship between space, time, and whiteness?

\section{Data and Methods}

Data for this chapter comes from a variety of sources: namely, the memes that are used to represent the ideas are popular on forums like 4chan, Instagram, reddit, Facebook, and Twitter. The images presented here come from Instagram data that was scraped in November 2017 as well as from the subreddit r/Europe and r/The_Europe, which was formed after $r$ /Europe was banned. On social media platforms, these memes are often accompanied by hashtags in order to allow for easy searching and discovery of them (like \#MAGA, \#Whiteldentity, \#WestlsTheBest, \#ProudBoys, to name a few).

Regardless of their platform of origin, these memes tend to spread across the digital world and enter into a variety of different communities, newsfeeds, and the like, making them the perfect vehicles for recruitment and mobilization. Using critical discourse analysis, I then attempt to make visible the ways that time, memory, and chronotopes are used in white supremacist memes, and implications for understanding online white supremacist propaganda moving forward.

\section{Potential Implications}

These activities push past the boundaries of physical space and have created global networks that are built on the ideology pushed in memes that provide a common vernacular (Hodge \& Hallgrimsdottir, 2019). Thus, "Western civilization" became less of a contained and abstract idea that fostered images of old castles and Crusaders, and became a tangible organizing effort through the linguistic practices of the online alt right. The alt right's digital nation transcends the constraints of borders and created a new logic of recruitment and mobilization by focusing in on the pan-ethnic "European" and "Western" identity and culture. The Internet also allows for the quick creation and adoption of new symbols that help to sustain the digital nation, and also for it to move from place to place when platforms ban, censor, and remove them (Benett, 2018; Shifman, 2014). 
By creating linguistic practices that are unique to the group, the alt right unifies itself despite its fractures. It is not only in the creation, but the consumption and sharing of memes that create community, helping to sustain it (Miller-ldriss, 2017). The alt-right use a variety of different images to provoke outrage, to build a collective identity, and to appeal to a loss of identity and through appeals to nostalgia and through the deployment of choronotopic speech. Nostalgia is created as a psychological state by provoking a longing for a time that never was, for something that hasn't been lost because it was never "had." These recruitment strategies tap into very base emotions and desires, and after the initial negative affect that they tap into, they promise a better future and hope.

\section{References}

Anderson, B. (2006). Imagined communities: Reflections on the origin and spread of nationalism (3rd ed.). Verso Books.

Benett, T. (2018, April 5). Gab Is the Alt-Right social network racists are moving to. Vice. https://www.vice.com/en_uk/article/ywxb95/gab-is-the-alt-right-socialnetwork-racists-are-moving-to

Daniels, J. (2009). Cyber racism: White supremacy online and the new attack on civil rights. Rowman \& Littlefield Publishers.

Glissant, E. (1992). Caribbean discourse: Selected essays. University of Virginia Press.

Hodge, E., \& Hallgrimsdottir, H. (2019). Networks of hate: The Alt-right, "troll culture," and the cultural geography of social movement spaces online. Journal of Borderlands Studies, 1-18.

Hughes, R. T. (2018). Myths America lives by: White supremacy and the stories that give us meaning. University of Illinois Press.

Miller-Idriss, C. (2017). Soldier, sailor, rebel, rule-breaker: Masculinity and the body in the German far right. Gender and Education, 29(2), 199-215.

Shifman, L. (2014). Memes in digital culture. MIT Press. 